\title{
STORYTELLING DAN ELECTRONIC WORD OF MOUTH DALAM MEMPENGARUHI KEPUASAN KONSUMEN (STUDI KASUS PADA SEGO NJAMOER DI SURABAYA)
}

\author{
${ }^{*}$ Ilham Ashari11, M Anang Firmansyah'2, \\ 1,2, Prodi Manajemen, Fakultas Ekonomi dan Bisnis, Universitas Muhammadiyah Surabaya \\ *) ilham.ash06@gmail.com
}

\section{Informasi Artikel}

Draft awal: Januari 2021

Revisi : Januari 2021

Diterima : Maret 2021

Available online: Maret 2021

Keywords: storytelling, electronic word of mouth, customer satisfaction

Tipe Artikel : Research paper

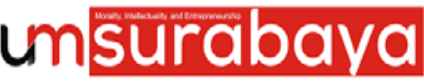

UNIVERSITAS MUHAMMADIYAH SURABAYA

Diterbitkan oleh Universitas Muhammadiyah Surabaya
ABSTRACT

This study aims to determine the effect of storytelling and electronic word ol mouth variables on consumer satisfaction at the "Sego Njamoer" food company. The number of samples in this study is 91 respondents. They are all consumers of 'Sego Njamoer" who have bought Sego Njamoer products. The sampling is using purposive sampling technique. The technique used in this study is to collect data using a questionnaire. The data are analyzea using multiple linear regression analysis techniques. The results of this study indicate that the storytelling and electronic word of mouth variables have an influence on the variable customer satisfaction simultaneously. The results of this study indicate that electronic word of mouth is the mosi dominant variable affecting consumer satisfaction.

Penelitian ini bertujuan untuk mengetahui pengaruh variabel storytelling dan electronic word of mouth terhadap kepuasan konsumen pada perusahaan makanan Sego Njamoer. Jumlah sampel dalam penelitian ini sebesar 91 responden. Mereka semua adalah konsumen Sego Njamoer yang pernah membeli produk Sego Njamoer. Pengambilang sampling menggunakan teknik purposive sampling. Teknik yang digunakan dalam penelitian ini untuk mengumpulkan data dengan menggunakan kuesioner. Analisis data menggunakan teknik analisis regresi linear berganda. Hasil penelitian ini menunjukkan bahwa variabel storytelling dan electronic word of mouth memiliki pengaruh terhadap variabel kepuasan konsumen secara simultan. Hasil penelitian ini menunjukkan bahwa electronic word of mouth merupakan variabel yang paling berpengaruh secara dominan terhadap kepuasan konsumen.

\section{PENDAHULUAN}

Perkembangan konsep komunikasi dan informasi saat ini telah mengalami pertumbuhan yang sangat pesat, pemanfaatannya sering kali digunakan dalam keperluan dunia bisnis digital sebagai sebuah cara yang efektif untuk mengenalkan serta menyebarkan informasi mengenai produk yang akan dijual. Dunia usaha juga telah menjadi trend yang sedang ramai diperbincangan oleh anak-anak muda sebagai sebuah hal yang harus dikerjakan dikemudian hari agar dapat mewujudkan kemandirian ekonomi di masa depan.

Teknologi dalam dunia digital atau internet yang terus berkembang tentu juga menjadi indikator tambahan dalam penyampaian pesan atau informasi ketika hendak melakukan pemasaran yang kekinian agar dapat diterima oleh seluruh calon konsumen potensial. Sehingga terjadilah tren pemasaran yang semula konvensional (offline) beralih menjadi digital (online). Saat ini, masyarakat mengganggap bahwa konsep pemasaran digital (online) dianggap lebih efektif dan efisien karena memungkinkan para pelanggan atau pembeli potensial mendapat berbagai informasi yang detail mengenai produk yang dicari melalui internet dengan biaya yang relatif rendah serta memiliki daya jangkauan yang lebih luas.

Indonesia merupakan negara yang saat ini menjadi salah satu pelaku perubahan konsep pemasaran dari konvensional ke digital, itu dibuktikan dengan banyak sekali UMKM di Indonesia yang menggunakan jejaring sosial di internet sebagai sarana untuk menyebarkan informasi mengenai produk yang dijual terhadap para konsumen. Banyak anak muda di Indonesia telah yang mendirikan sebuah usaha baru dan menggunakan media sosial untuk keperluan pemasaran bisnisnya. Menurut Survei Asosiasi Jasa 
Penyelenggara Internet Indonesia (AJPII) pada tahun 2017, pengguna internet Indonesia mencapai 143,26 juta jiwa dari total penduduk Indonesia sebanyak 262 juta jiwa.

Salah satu UMKM karya anak muda Indonesia yang sedang menjadi perbincangan saat ini ialah Sego Njamoer. Sego Njamoer merupakan UMKM yang berfokus pada bidang kuliner, usaha ini juga menggunakan konsep storytelling marketing sebagai sarana untuk menumbuhkan kepuasan terhadap konsumen. Bukan hanya itu, usaha ini juga menggunakan electronic word of mouth sebagai upaya diferensiasi pemasaran dalam mensiasati para konsumen untuk mengenal lebih jauh latar belakang usaha yang diciptakan yang berbasis sociopreneurship. Strategi tersebut dianggap mampu menumbuhkan jumlah outlet Sego Njamoer dari Januari-Desember 2018 yang berjumlah 29 outlet menjadi 35 outlet pada Januari-April 2019 di Surabaya saja. Itu membuktikan bahwa terjadi banyak permintaan pembeliaan di pasar yang di barengi dengan pertumbuhan jumlah outlet yang signifikan. Namun pada beberapa kasus, jumlah outlet Sego Njamoer mengalami penurunan jumlah outlet di daerah-daerah tertentu. Indonesia merupakan negara yang saat ini menjadi salah satu pelaku perubahan konsep pemasaran dari konvensional ke digital, itu dibuktikan dengan banyak sekali UMKM di Indonesia yang menggunakan jejaring sosial di internet sebagai sarana untuk menyebarkan informasi mengenai produk yang dijual terhadap para konsumen. Banyak anak muda di Indonesia telah yang mendirikan sebuah usaha baru dan menggunakan media sosial untuk keperluan pemasaran bisnisnya. Menurut Survei Asosiasi Jasa Penyelenggara Internet Indonesia (AJPII) pada tahun 2017, pengguna internet Indonesia mencapai 143,26 juta jiwa dari total penduduk Indonesia sebanyak 262 juta jiwa.

Salah satu UMKM karya anak muda Indonesia yang sedang menjadi perbincangan saat ini ialah Sego Njamoer. Sego Njamoer merupakan UMKM yang berfokus pada bidang kuliner, usaha ini juga menggunakan konsep storytelling marketing sebagai sarana untuk menumbuhkan kepuasan terhadap konsumen. Bukan hanya itu, usaha ini juga menggunakan electronic word of mouth sebagai upaya diferensiasi pemasaran dalam mensiasati para konsumen untuk mengenal lebih jauh latar belakang usaha yang diciptakan yang berbasis sociopreneurship. Strategi tersebut dianggap mampu menumbuhkan jumlah outlet Sego Njamoer dari Januari-Desember 2018 yang berjumlah 29 outlet menjadi 35 outlet pada Januari-April 2019 di Surabaya saja. Itu membuktikan bahwa terjadi banyak permintaan pembeliaan di pasar yang di barengi dengan pertumbuhan jumlah outlet yang signifikan. Namun pada beberapa kasus, jumlah outlet Sego Njamoer mengalami penurunan jumlah outlet di daerah-daerah tertentu.

\section{METODE PENELITIAN}

Pada penelitian ini menggunakan pendekatan atau metodologi kuantitatif yaitu teknik analisis data yang digunakan dan diarahkan untuk menjawab rumusan masalah dan menguji hipotesis. Penelitian ini menggunakan teknik purposive sampling untuk menentukan sampel penelitiannya serta menggunakan alat analisis SPSS 20. Berdasarkan jumlah total populasi dalam penelitian ini adalah konsumen Sego Njamoer sebanyak 91 responden dari 1000 konsumen Sego Njamoer di Surabaya.

\section{HASIL PENELITIAN}

\section{Uji asumsi klasik}

Uji normalitas digunakan untuk mengetahui apakah hasil suatu data tersebut mengikuti persebaran yang normal atau tidak. Uji tersebut dilakukan dengan menggunakan metode Kolmogorov Smirnov agar dapat mengetahui nilai residual tersebut berdistribusi normal atau tidak. Model regresi yang baik adalah memiliki nilai residual yang yang berdistribui dengan normal, yakni hasil nilai residual tersebut harus $>0,05$, maka data terdistribusi normal atau $\mathrm{HO}$ diterima.

Berikut adalah hasil uji normalitas pada penelitian ini:

\section{Tabel 1. Uji Normalitas}

\begin{tabular}{lc}
\hline & Unstandardized Residual \\
\hline $\mathrm{N}$ & 91 \\
Kolmogorov-Smirnov Z &, 669 \\
Asymp. Sig. (2-tailed) &, 763 \\
\hline
\end{tabular}

Berdasarkan hasil uji normalitas pada tabel 4.10 dapat diketahui bahwa data yang digunakan oleh peneliti berdistribusi secara normal, hal tersebut dibuktikan dengan nilai residual yang berjumlah 0,763 yang berarti $>0,05$.

Uji multikolinearitas digunakan untuk menunjukkan suatu hubungan linear antar variabelvariabel bebas dalam model model regresi pada penelitian ini. Uji multikolinearitas pada penelitian ini menggunakan metode tolerance dan VIF.

Cara yang digunakan untuk mengetahui multikolinearitas adalah dengan melihat besarnya nilai variabel inflation factor (VIF) dan nilai tolerance. Adapun hasil uji multikolinearitas pada penelitian ini adalah sebagai berikut: 
Tabel 2. Hasil Uji Multikolinieritas

\begin{tabular}{|c|c|c|c|c|}
\hline \multirow{2}{*}{\multicolumn{2}{|c|}{ Model }} & \multirow[t]{2}{*}{ Sig. } & \multicolumn{2}{|c|}{ Collinearity Statistics } \\
\hline & & & Tolerance & VIF \\
\hline \multirow{3}{*}{1} & (Constant) & ,004 & & \\
\hline & storytelling & ,091 & ,650 & 1,537 \\
\hline & $\begin{array}{l}\text { electronic word of } \\
\text { mouth }\end{array}$ & ,000 & 650 & 1,537 \\
\hline
\end{tabular}

Berdasarkan tabel 2 pada hasil uji multikolinearitas diatas dapat diketahui bahwa nilai tolerance sebesar 0,650 $>0,10$ dan nilai VIF sebesar $1,537<10$. Hal ini memberi arti bahwa dalam persamaan regresi penelitian ini tidak ditemukan adanya multikolinearistas. Sehingga dapat disimpulkan bahwa variabel-variabel bebas pada penelitian ini tidak terjadi masalah multikolinearitas.

Uji Heterokedastisitas digunakan untuk mengetahui ada atau tidaknya kesamaan varian dari nilai-nilai residual untuk semua pengamatan pada model regresi. Penghitungan uji heterokedastisitas pada penelitian ini dilakukan dengan menggunakan grafik Rank Spearman yang berbentuk tabel. Apabila variance dari residual satu pengamatan ke pengamatan yang lain tetap, maka disebut dengan istilah homoskedastisitas, namun jika berbeda maka disebut dengan heteroskedastisitas.

Berdasarkan data pada tabel 4.12 Rank Spearman diatas, dapat diketahui bahwa nilai sig storytelling sebesar 0,733 dan nilai sig electronic word of mouth sebesar 0,557, semua nilai sig variabel $X$ pada penelitian ini adalah $>0,05$ yang berarti tidak terjadi gejala heteroskedastisitas. Model regresi penelitian ini dapat dikatakan layak digunakan untuk memprediksi variabel kepuasan konsumen (Y) berdasarkan variabel-variabel yang mempengaruhinya, yaitu variabel storytelling dan electronic word of mouth.

Uji asumsi klasik yang telah dilakukan peneliti menunjukkan bahwa model persamaan regresi linear bebas dari asumsi dasar (klasik). Sehingga pengambilan keputusan melalui Uji F dan Uji $\mathrm{T}$ yang akan dilakukan tidak akan bias atau sesuai dengan tujuan penelitian.

Tabel 3. Hasil Uji Heteroskedastisitas

\begin{tabular}{|c|c|c|c|}
\hline & & & $\begin{array}{l}\text { Unstandardized } \\
\text { Residual }\end{array}$ \\
\hline \multirow{4}{*}{$\begin{array}{l}\text { Spearman's } \\
\text { rho }\end{array}$} & $\begin{array}{c}\text { Total } \\
\text { X1 }\end{array}$ & $\begin{array}{l}\text { Correlation Coefficient } \\
\text { Sig. (2-tailed) } \\
\text { N }\end{array}$ & $\begin{array}{c}-, 036 \\
, 733 \\
91\end{array}$ \\
\hline & $\begin{array}{l}\text { Total } \\
\text { X2 }\end{array}$ & $\begin{array}{l}\text { Correlation Coefficient } \\
\text { Sig. (2-tailed) } \\
\text { N }\end{array}$ & $\begin{array}{c}-, 062 \\
, 557 \\
91 \\
\end{array}$ \\
\hline & $\begin{array}{l}\text { Unsta } \\
\text { ndard } \\
\text { ized }\end{array}$ & $\begin{array}{l}\text { Correlation Coefficient } \\
\text { Sig. (2-tailed) }\end{array}$ & $\begin{array}{c}1,000 \\
.\end{array}$ \\
\hline & $\begin{array}{l}\text { Resid } \\
\text { ual }\end{array}$ & $\mathrm{N}$ & 91 \\
\hline
\end{tabular}

Analisis Regresi Linier Berganda

Perhitungan regresi linier berganda antara storytelling dan electronic word of mouth terhadap kepuasan konsumen dengan dibantu program SPSS 20 dalam proses perhitungannya dapat diperoleh hasil sebagai berikut:

Tabel 4. Hasil Analisis Regresi Linear Berganda

\begin{tabular}{lrr}
\hline Model & \multicolumn{2}{c}{ Unstandardized } \\
& \multicolumn{2}{c}{ Coefficients } \\
\cline { 2 - 3 } & \multicolumn{1}{c}{ B } & Std. Error \\
\hline (Constant) & 5,621 & 1,912 \\
storytelling &, 112 &, 066 \\
electronic word of mouth &, 182 &, 033 \\
\hline
\end{tabular}

Berdasarkan data diatas, dapat dilihat dari besar nilai konstantanya yaitu sebesar 5,621, maka dapat disimpulkan bahwa semua variabel independen pada penelitian ini berpengaruh positif terhadap Y atau variabel dependen.

Pengaruh variabel independen storytelling (X1) terhadap kepuasan konsumen (Y) dapat diketahui dari nilai koefisien regesi 0,112 atau $11,2 \%$ koefisien bernilai positif, artinya antara variabel storytelling dan variabel kepuasan konsumen terjadi hubungan positif. Kenaikan storytelling akan mengakibatkan kenaikan pada kepuasan konsumen (Y).

Variabel bebas electronic word of mouth (X2) memiliki nilai koefisien regresi sebesar 0,182 atau 18,2\%. Maka dapat disimpulkan bahwa electronic word of mouth (X2) memiliki hubungan positif terhadap kepuasan konsumen. Apabila electronic word of mouth (X2) mengalami kenaikan, maka akan berakibat pada variabel kepuasan konsumen.

\section{Uji Hipotesis}

Uji F dilakukan bertujuan untuk mengetahui pengaruh storytelling dan electronic word of mouth berpengaruh secara bersama-sama atau simultan terhadap variabel kepuasan konsumen. Hal ini dilakukan untuk menjawab rumusan masalah pada penelitian ini. Cara menggunakan uji ini adalah dengan membandingkan nilai signifikansi antara Fhitung dan Ftabel. Hasil pengujian pada penelitian ini dapat dilihat pada tabel 4.14 adalah sebagai berikut.

\section{Tabel 4. Hasil Uji F}

\begin{tabular}{lcl}
\multicolumn{3}{c}{ ANOVA $^{\mathbf{a}}$} \\
\hline Model & F & Sig. \\
\hline Regression & 34,934 &, $000^{\mathrm{b}}$ \\
Residual & & \\
Total & & \\
\hline
\end{tabular}


Berdasarkan data hasil uji F pada tabel 4.13, dapat diketahui bahwa terjadi pengaruh X1 dan X2 secara simultan terhadap variabel kepuasan konsumen, itu dibuktikan dengan jumlah nilai signifikan sebesar $0,000<0,05$ dan nilai $\mathrm{F}$ hitung 34,934 > F tabel 3,10, sehingga dapat disimpulkan bahwa variabel storytelling (X1) dan electronic word of mouth (X2) berpengaruh secara simultan terhadap variabel kepuasan konsumen $(\mathrm{Y})$.

Uji t digunakan untuk mengetahui bukti pengaruh signifikan antara variabel bebas yang terdiri dari storytelling dan electronic word of mouth secara parsial memiliki pengaruh terhadap variabel terikat kepuasan konsumen. Cara menggunakan uji ini adalah dengan membandingkan nilai thitung dan nilai ttabel pada penelitian ini. Hasil uji pada penelitian ini dapat dilihat pada tabel 4.16 sebagai berikut:

\section{Tabel 5. Hasil Uji t}

\begin{tabular}{|c|c|c|c|c|}
\hline \multicolumn{5}{|c|}{ Model Summary } \\
\hline Model & $\mathrm{R}$ & $\begin{array}{c}\mathrm{R} \\
\text { Square }\end{array}$ & $\begin{array}{c}\text { Adjusted R } \\
\text { Square }\end{array}$ & $\begin{array}{l}\text { Std. Error of } \\
\text { the Estimate }\end{array}$ \\
\hline 1 &, $665^{\mathrm{a}}$ & ,443 & ,430 & 1,424 \\
\hline
\end{tabular}

Berdasarkan data diatas, dapat diketahui nilai sig X1 terhadap Y sebesar 0,091, sedangkan nilai t hitung X1 terhadap $\mathrm{Y}$ sebesar 1,710. Hal ini memiliki arti bahwa variabel storytelling tidak berpengaruh terhadap $\mathrm{Y}$ dikarenakan nilai, dikarenakan nilai t hitung X1 1,710 < 1,98729 atau hipotesis ditolak. Sedangkan nilai Sig X2 terhadap Y $=0,000$ dan nilai $\mathrm{t}$ hitung $\mathrm{X} 2$ terhadap $\mathrm{Y}=5,587$ artinya electronic word of mouth berpengaruh terhadap Y, hal ini terjadi karena nilai t hitung X2 5,587 > 1,98729 atau hipotesis diterima.

Uji koefisien determinasi dilakukan untuk mengetahui seberapa besar pengaruh antara variabel bebas yang terdiri dari variabel storytelling dan electronic word of mouth dengan variabel terikat yakni kepuasan konsumen. Pada penelitian ini, penghitungan uji menggunakan bantuan komputer dengan software statistical program for sciense (SPSS) 20. Berikut ini adalah hasil perhitungan uji koefisien determinasi pada penelitian ini.

Tabel 6 Hasil Uji Koefisien Determinasi

\begin{tabular}{lcc}
\hline Model & $\mathrm{t}$ & Sig. \\
\hline (Constant) & & \\
storytelling & 2,940 &, 004 \\
electronic word of mouth & 1,710 &, 091 \\
\hline
\end{tabular}

Berdasarkan hasil uji koefisien determinasi diatas, menunjukkan nilai $\mathrm{R}$ sebesar 0,665. Hal ini menunjukkan bahwa hubungan atau korelasi antara faktor-faktor yang mempengaruhi kepuasan konsumen adalah kuat karena $>0,5$. Nilai $\mathrm{R}$ square sebesar 0,443 atau $44,3 \%$. Hal ini menunjukkan bahwa variabel kepuasan konsumen yang dapat dijelaskan oleh storytelling dan elctronic word of mouth adalah sebesar 44,3\%, sedangkan sisanya adalah 55,7\% dijelaskan oleh faktor-faktor lain yang tidak disertakan dalam model penelitian ini. Hasil ini bisa dikatakan bahwa variabel-variabel bebas pada penelitian ini masih memiliki presentase pengaruh yang sedikit dikarenakan pada penelitian sebelumnya yang dilakukan Hermansyah (2015) beranggapan bahwa kualitas layanan menjadi faktor penentu utama bagi konsumen Sego Njamoer dalam mendapatkan kepuasan konsumen secara maksimal ketika berbelanja atau mengkonsumsi produkproduk Sego Njamoer.

\section{PEMBAHASAN}

Pengaruh Storytelling dan Electronic word of mouth secara simultan terhadap Kepuasan Konsumen (Studi Kasus Pada Sego Njamoer di Surabaya).

Berdasarkan hasil penelitian ini, uji simultan yang diperoleh dari uji F menunjukkan nilai Fhitung 34,934 > Ftabel 3,10. Hal menjelaskan bahwa terdapat pengaruh variabel $\mathrm{X} 1$ storytelling dan variabel X2 electronic word of mouth secara simultan terhadap variabel Y kepuasan konsumen. Penelitian ini sejalan dengan hasil penelitian sebelumnya milik Alfahmi et. al (2018) yang berjudul Destination Brand Storytelling: Analisis Naratif Video The Journey to A Wonderful World Kementerian Pariwisata. Penelitian tersebut beranggapan bahwa pendekatan storytelling dalam destination branding suatu negara membentuk identitas wisata. Penelitian ini membuktikan bahwa storytelling dan electronic word of mouth dapat berpengaruh terhadap kepuasan konsumen pada Sego Njamoer. Pemasar Sego Njamoer berhasil menggunakan konsep storytelling dan electronic word of mouth dalam memenuhi kepuasan konsumennya. Story yang dibawakan oleh Sego Njamoer berupa petani jamur, makanan praktis yang bergizi bagi mahasiswa yang kemudian dimuat dalam media sosial di internet hingga memunculkan electronic word of mouth atau percakapan di media sosial mampu menjadi hal yang menarik bagi konsumen untuk memenuhi kepuasannya ketika berbelanja di Sego Njamoer. 
Variabel Electronic word of mouth paling berpengaruh dominan terhadap Kepuasan Konsumen (Studi Kasus Pada Sego Njamoer di Surabaya).

Berdasarkan hasil penelitian diatas yang terdiri dari variabel storytelling dan electronic word of mouth, dapat diketahui bahwa nilai sig X1 terhadap Y sebesar 0,091, sedangkan nilai t hitung X1 terhadap Y sebesar 1,710. Hal ini memiliki arti bahwa variabel storytelling tidak berpengaruh terhadap Y dikarenakan nilai, dikarenakan nilai $\mathrm{t}$ hitung X1 1,710<1,98729 atau hipotesis ditolak. Sedangkan nilai Sig X2 terhadap Y $=0,000$ dan nilai t hitung $\mathrm{X} 2$ terhadap $\mathrm{Y}=5,587$ artinya electronic word of mouth berpengaruh terhadap $\mathrm{Y}$, hal ini terjadi karena nilai thitung X2 5,587 > 1,98729 atau hipotesis diterima. Hal ini menunjukkan bahwa hasil pembahasan pada penelitian ini sejalan dengan penelitian sebelumnya milik Prabowo,et.al (2015) yang berjudul Pengaruh Electronic Word Of Mouth (E-Wom) Terhadap Purchase Intention (Studi Kasus Pada Go-Jek Indonesia). Penelitian tersebut dilakukan untuk mengatahui electronic word of mouth dan pengaruhnya terhadap purchase intention dengan Gojek Indonesia sebagai objek penelitian. Pada penelitian tersebut, secara parsial electronic word of mouth memiliki pengaruh positif dan signifikan terhadap variabel minat beli konsumen. Hal ini dapat terjadi karena banyak kalangan konsumen yang belum paham benar tentang story yang dibawakan Sego Njamoer dibanding dengan adanya dampak konten yang di sebarkan di media sosial Sego Njamoer. Para konsumen Sego Njamoer lebih merasa mendapat kepuasan jika banyak konten-konten baru dan kreatif yang muncul pada akun resmi Sego Njamoer. Hal itulah yang membuat konsumen. Variabel kepuasan konsumen yang dapat dijelaskan oleh storytelling dan electronic word of mouth adalah sebesar 44,3\%, sedangkan sisanya adalah 55,7\% dijelaskan oleh faktor-faktor lain yang tidak disertakan dalam model penelitian ini.

\section{SIMPULAN DAN SARAN}

\section{Simpulan}

Berdasarkan hasil penelitian sebagaimana yang telah dibahas pada bab sebelumnya, beberapa hal yang dapat disimpulkan dalam penelitian ini diantaranya adalah sebagai berikut:

1. Variabel independen yang terdiri dari varibel $\mathrm{X} 1$ storytelling dan variabel X2 electronic word of mouth memiliki pengaruh simultan terhadap variabel kepuasan konsumen (Y). Pada penelitian ini, kedua varibel independen mempengaruhi kepuasan konsumen Sego
Njamoer, semakin banyak konsumen memahami storytelling yang disampaikan melalui electronic word of mouth, maka kepuasan konsumen akan semakin bertambah pula.

2. Berdasarkan hasil penelitian ini, dapat diketahui bahwa electronic word of mouth merupakan variabel independen yang memiliki pengaruh lebih besar terhadap kepuasan konsumen apabila dibandingkan dengan storytelling secara parsial. Tingginya intensitas pengaruh electronic word of mouth dalam mempengaruhi kepuasan konsumen dapat diamati dari banyaknya konsumen Sego Njamoer yang mengetahui informasi Sego Njamoer dari media sosial di internet. Semakin sering konsumen membaca tentang informasi produk Sego Njamoer di internet, maka Sego Njamoer akan semakin melekat di benak konsumen untuk menyediakan produk dan menjadikan Sego Njamoer sebagai pilihan.

\section{Saran}

1. Bagi perusahaan disarankan untuk lebih menonjolkan storytelling yang menjadi latarbelakang berdirinya usaha tersebut serta lebih gencar mensosialisasikan storytelling Sego Njamoer mengenai petani jamur dan segala keterbatasan nya dalam memasarkan produknya di media sosial. Perkembangan teknologi yang semakin pesat mengharuskan Sego Njamoer untuk selalu memiliki inovasiinovasi dalam memasarkan produk olahan jamur tersebut di internet berbasis electronic word of mouth. Hal tersebut dalam memudahkan Sego Njamoer dalam membidik target pasarnya agar tetap konsisten menjadi konsumen setia Sego Njamoer. Perusahaan dapat memberikan konten-konten kreatif yang memiliki kuantitas cukup banyak serta berisi informasi-informasi yang manarik mengenai Sego Njamoer. Hal tersebut bertujuan untuk menarik konsumen-kosumen Sego Njamoer dalam upaya mengakses informasi mengenai produk Sego Njamoer di internet.

2. Bagi peneliti selanjutnya, yang ingin melakukan penelitian dengan tema yang sama disarankan untuk menggunakan metode kualitatif dalam penelitiannya, karena masih 
sedikit penelitian yang membahas storytelling di Indonesia.

\section{DAFTAR PUSTAKA}

Fatihudin,Didin, 2015, Metode Penelitian Untuk Ilmu Ekonomi Akuntansi dan Manajemen, Zifatama Publishing, Cetakan Pertama, Sidoarjo.

Firmansyah,Anang dan Mahardhika,Budi, 2018, Pengantar Manajemen, Deepublish, cetakan pertama, Yogyakarta.

Fatihudin,Didin, dan Firmansyah,Anang, 2019 Pemasaran Jasa, Deepublish Publisher, Cetakan Pertama, Yogyakarta.

Firmansyah,Anang dan Fatihudin,Didin, 2017, Globalisasi Pemasaran, Deepublish Publisher, Cetakan Pertama, Yogyakarta.

Kotler,Philip dan Keller,Kevin, 2009, Manajemen Pemasaran, Airlangga, Edisi ke-13, Jilid 2, Jakarta.

Laudon,Kenneth dan Laudon,Jane, 2015, Management Information Systems Managing the Digital Firm Thirteenth Edition, Salemba Empat, Edisi ke-13, Jakarta Selatan.

Suwarduki,Puspa., $\quad$ Yulianto,Edy dan Marwadi,Kholid.,Agustus, 2016, "Pengaruh Electronic Word Of Mouth Terhadap Citra Destinasi Serta Dampaknya Pada Minat Dan Keputusan Berkunjung Di Indonesia”, page 34.

Hafizah,Nurul dan Ariyanti,Maya.,Januari, 2019, "Pengaruh The Public Good And Knowledge Self-Efficacy Terhadap Niat Konsumen Melakukan Electronic Word Of Mouth (Studi Pada Pengguna Kaskus Di Indonesia)”, page 19-20.

Melinda,Marsela.,Sari,Puspita, dan Prasetio,Adhi.,Agustus, 2018, “Analisis Pengaruh Electronic Word Of Mouth Terhadap Purchase Intention Pada Followers Akun Instagram Adorable Project”, page 1661

Pravitasari,Nirakatriena.,Arifin,Zainul, dan Mawardi,Kholid., April, 2018, "Pengaruh Storytelling Marketing Terhadap Brand Equity Dan Keputusan Pembelian (Survei Pada Video Iklan Allure Matcha Latte Story di Youtube)", page 32.

Shopiani,Puji., 2008, "Peran Storytelling Sebagai Sarana Promosi Perpustakaan TK/SD ALAZHAR Pondok Labu”, page 21.
Ratnasari,Nunik., Maret, 2016, "Pengaruh Social Media Marketing Dan Perilaku Konsumen Online Di Kota Subang Terhadap Brand Story Pada Aplikasi Instant Messenger Line”, page 52-53

Maharani ,et al.,Februari, 2018, "Pengaruh Green Marketing dan Brand Equity Terhadap Purchase Intention Air Minum Dalam Kemasan Merek Aqua (Studi Pada Masyarakat di Kabupaten Jombang)”, page 68

Fog,Klaus, et.al, 2010, Storytelling Branding in Practice, Spinger, Second Edition, Copenhagen, DenmarkNoorainy, F. (2017). Pengaruh Lingkungan Kerja Fisik dan Non Fisik Terhadap Kinerja Pegawai Pada Sekretariat Daerah Kabupaten Pangandaran. Journal of Management Review, 2(1):75-85.

Nur'aini DF, F. (2017). Paduan Praktis Evaluasi Kinerja Karyawan. Yogyakarta: Quadrant.

Pratiwi, D., Lie, D., Efendi, \& Chandra, E. (2017). Pengaruh Disiplin Kerja dan Lingkungan Kerja Terhadap Kinerja Pegawai Pada PT Bank Sumut Syariah Cabang Pematangsiantar. Jurnal MAKER, 3(1): 7381.

Sarwono, P. (2015). Landasan Psikologi Proses Pendidikan. Jakarta: Bumi Aksara.

Satori, D., \& Komariah, A. (2017). Metodologi Penelitian Kualitatif. Bandung: Afabeta.

Sedarmayanti. (2011). Manajemen Sumber Daya Manusia. Yogyakarta: STIE YKPN.

Sedarnayanti. (2009). Pengembangan Kepribadian Pegawai. Bandung: Mandar Maju.

Soelistya, D. (2017). Membangun Komitmen Karyawan. Sidoarjo: Nizamial Learning Center.

Sudaryo, Y., Aribowo, A., \& Sofiati, N. A. (2018). Manajemen Sumberdaya Manusia, Kompensasi Tidak Langsung dan Lingkungan Kerja Fisik. Yogyakarta: CV Andi Offset.

Sugiyono. (2015). Metode Penelitian Kuantitatif, Kualitatif dan R\&D. Bandung: Afabeta.

Sugiyono. (2018). Metode Penelitian Kualitatif. Bandung: Elfabeta.

Sunyoto, D. (2015). Penelitian Sumber Daya Manusia (Teori, Kuesioner, Alat Statistik dan Contoh Riset). Yogyakarta: Caps Publishing. 